\title{
$\underline{\text { MORAL INNATISM AND LEGAL THEORY }}$
}

\section{Carlos MONTEMAYOR}

\begin{abstract}
Resumen:
En este artículo se discute una propuesta denominada "Gramática moral universal" y sus implicaciones para la teoría del derecho. El autor explica la relevancia de esta propuesta en relación con los enfoques iusnaturalistas sobre la legislación y la capacidad moral. A su vez, el estudio presenta diversas objeciones a esta propuesta y ofrece evidencia conductual relativa a su plausibilidad como una teoría científica de la competencia moral. Una conclusión importante del artículo, según el autor, es que los juristas y los abogados contemporáneos tienen la responsabilidad de ir más allá de su propio campo y de empezar a tomar un papel más activo en el estudio interdisciplinario de la conducta social.
\end{abstract}

Abstract:

In this paper I critically assess a proposal called 'Universal Moral Grammar' and its implications for legal theory. I explain its relevance with respect to Natural Law approaches to legislation and our moral capacity. I present objections to this proposal and offer behavioral evidence concerning its plausibility as a scientific theory of moral competence. An important conclusion of the article is that lawyers and legal theorist have now the responsibility to look beyond their field, and start taking a more proactive role in the interdisciplinary study of social behavior. 
Summary: I. Introduction. II. Universal Moral Grammar. III. First Problem: Making Sense of Data. IV. Second problem: intuitionism and UMG. V. Third Problem: Evolution, Behavior and UMG. VI. Conclusion: Law and UMG.

\section{INTRODUCTION}

The source and justification of social norms, and legal systems in particular, is one of the oldest and most important philosophical problems. It involves religious, socio-economic, cultural, and philosophical considerations concerning free will, political power and the very notion of rationality. Identifying the sources of morality and law would have enormous repercussions to the way we live and understand ourselves.

The problem of identifying the sources of morality and law raises the question: what is the relationship between law and morality? A compelling answer to this question is that there is a single and universal source of morality and law, which can be characterized as a "moral sense" or a psychological capacity to represent moral and legal obligations. Historically, legal theorists have argued that our moral sense is the source of legitimate power and legislation, as well as the standards for morality. As Mahlmann and Mikhail (2005) say:

The history of philosophy is rich with different accounts of the foundations of morality and law. The significance of this history is more than merely academic. Theories of morality and law specify the duties and rights of individuals, the scope and limits of state authority, and the legitimate distribution of wealth and power in a community. One classic, recurring view in the history of philosophy holds that human beings are capable of recognizing material standards for a just and morally good social order by a special cognitive capacity. ${ }^{1}$

1 Mahlmann, M. and Mikhail, J., "Cognitive Science, Ethics, and Law", in Bankowski, Zenon (ed.), Epistemology and Ontology, Franz Steiner Verlag, 2005, pp. 95-102. 
Appeals to a universal and perennial Natural Law that originates from our moral sense characterize this sense as a) a capacity, based on our feelings and emotions, to recognize and distinguish good from bad actions (British Empiricism) or b) A capacity to determine moral and legal content based on rationality and universal principles (Normative Ethics). ${ }^{2}$ Recently, accounts of our moral sense have taken a new direction that adds yet another level of complexity to debates about the source of morality and legal systems. Identifying our moral sense and its true nature has turned into a scientific enterprise. At the core of this scientific venture is the question: can we identify our moral sense with the tools of cognitive science? Is it based on rational principles or determined by our emotions? And, is it truly universal in the sense that all humans possess it?

John Rawls suggested in A Theory of Justice (1971) that our capacity to represent moral principles is similar in relevant respects to our capacity to represent grammatical rules, which is a view that does not fit squarely within the emotional or normative approaches. ${ }^{3}$ Exactly how Rawls' suggestion should be interpreted has been a topic of much debate. Fortunately, the work of John Mikhail provides us with a careful assessment of Rawls' linguistic analogy that addresses specifically fundamental issues concerning its interpretation.

In section II, I present Mikhail's account of Rawls' linguistic analogy and explain the merits of Mikhail's arguments in favor of the existence of a Universal Moral Grammar (UMG). In section III, I present objections that have been made against the interpretation of the psychological evidence suggesting the existence of UMG, and evaluate

2 The history of Natural Law is deeply related to religion and the value of human life. I will not delve into religious considerations because even in religious formulations of Natural Law, cognitive capacities must play a role in the acquisition of a moral sense, which allows us to distinguish good from evil. And it is this moral sense that interests me.

3 Rawls, John, A Theory of Justice Cambridge, MA., Harvard University Press Particularly Section 9, 1971. 
their plausibility. In section IV, I describe challenges to UMG based on recent criticism of intuitionism in ethics. Finally, in section V, I argue that even if we assume that the objections raised in sections III and IV are satisfactorily answered by a scientific formulation of UMG, the most serious challenges for UMG come from its evolutionary and social implications, particularly concerning moral standing and the evolution of social behavior.

\section{UNIVERSAL MORAL GRAMMAR}

To understand Rawls' linguistic analogy, it is essential to explain Noam Chomsky's notion of Universal Grammar (UG) and, in particular, the concepts of I and E-language. ${ }^{4}$ I-language refers to the set of mental representations that constitute our linguistic competence. I-language ('I' stands for 'internal') is an abstract set of computational principles that operate without our being aware of them. These computational instructions for representing language are instantiated in our brain. Chomsky proposed that given the poverty of linguistic stimuli, the acquisition of language by humans reveals that our linguistic competence is innate. This means that our language faculty is the result of our genetic make up, and not of exposure to stimuli and external guidance.

In contrast, E-language is the external or public manifestation of the internal representation of language on which linguistic competence depends. Unlike I-language, E-language is learned and humans are aware of the express principles and symbols that constitute E-language. E-languages, like Greek and Arabic, are the result of cultural, historical and social contingencies. However, all humans are endowed with the same language faculty, the same set of syntactic rules for structuring language. This is the main idea behind Chomsky's notion of UG.

4 See Chomsky, Noam, Knowledge of Language: Its Nature, Origin, and Use New York, NY, Praeger, 1986. 
It would be impossible to learn Greek, Arabic, or any other language without UG. However, how much linguistic information is stored in UG? Although there is no consensus as to how to answer this question, there is convincing evidence that humans are innately endowed with UG, which is either a set of abstract principles that inform language acquisition, or a set of principles and parameters that require external information to determine their specific application.

The distinction between I and E-language is crucial to understand the notions of operative and express principles. Operative principles are innate and determine our language competence. We are not aware of them and cannot articulate their content or describe how they work. We simply apply them when we hear or read a sentence. These principles give us a sense of grammaticalness, which all humans have. The express principles of E-language are those that we can articulate explicitly and of which we are aware.

Rawls' famous 'linguistic analogy' is that our sense of morality is similar to our sense of grammaticalness and that, therefore, it must have a similar cognitive basis and explanation. According to Mikhail, the heart of Rawls' linguistic analogy is a set of questions pertaining to I-language. 5 These questions, which Mikhail labels as specific problems, are:

1) What constitutes I-language? (the problem of descriptive adequacy) is equivalent to: what constitutes I-morality?

2) How is I-language acquired? (the problem of explanatory adequacy) is equivalent to: how is I-morality acquired?

3) How is I-language put to use? (the problem of performance or actual behavior) is equivalent to: how is I-morality put to use?

5 Mikhail, John, Rawls' Linguistic Analogy Dissertation, 2000, p. 88. 
Analogously to language, moral competence would be determined by I-morality, which all humans are, presumably, innately endowed with. The acquisition of I-morality will likely involve evolutionary and genetic processes. Moral performance, or how our moral competence is put to use in our social behavior, will depend on external factors. As Mikhail explains, these questions do not exhaust Rawls' linguistic analogy, but they are the most important ones. ${ }^{6}$

There are three reasons why Rawls' linguistic analogy is compelling. First, it poses an empirical issue, one that psychologists and neuroscientists can investigate in their labs. Certainly, it is better to take a scientific approach to moral innatism, rather than relying on philosophical speculation. Second, it opens the possibility of evolutionary accounts of our moral capacity. And third, it allows us to draw comparisons between what psychologists find in their labs with concrete human behavior. Particularly, if our moral competence is rich enough, it presents a persuasive reformulation of the Natural Law and its relationship to concrete legal systems, which could be conceived as instantiations of E-morality. These are new and exciting topics for current legal theorizing.

Rawls' linguistic analogy can be criticized from a theoretical or an empirical perspective. In this paper, I raise issues that are largely empirical, but that touch on some fundamental theoretical considerations, such as the role of intuitions in morality. Most of my objections are aimed at problem (1) 'descriptive adequacy', but I will explain why questions (2) and (3) of the analogy are also problematic, mainly in section $\mathrm{V}$. In the next section, I critically assess a series of experiments that have been interpreted as evidence in favor of UMG.

6 For a detailed account of Rawls' linguistic analogy and a defense of it against objections by Thomas Nagel and Ronald Dworkin see John Mikhail's Disseratation, op. cit., n. 5. 


\section{First Problem: Making Sense of the Data}

Most of the research that has been conducted on UMG focuses on question (1) of the analogy: what constitutes I-morality? Answering this question is the most critical step towards identifying an innate moral sense, or moral competence, that would serve as the basis of the linguistic analogy. There are significant challenges to test the moral competence of individuals. The most important one is, how to design an experiment in which people's operative principles, rather than their express or explicitly understood principles, are tested?

Moral dilemmas offer a unique opportunity to test the principles underlying subjects' responses to moral scenarios. For instance, the principle of the double effect, proposed by moral philosophers, holds that harming an individual for the greater good is morally permissible if such harm is a foreseen side effect, rather than a necessary means to achieve the desired result. The classic examples of the principle of the double effect are 'trolley cases', in which a person is killed in order to save the lives of five people. In one case the person dies as a foreseen side effect and in the other, she dies as a means to save the five people. ${ }^{7}$

The reason why these are dilemmas is because harm is inevitable. Yet people consider the side effect scenario as morally permissible and the necessary means scenario as morally impermissible, even though the outcome is the same. Moral philosophers use the contrast between these two scenarios as evidence that our intuitions favor a Kantian, rather than a utilitarian approach to moral issues. However, these intuitions were not empirically tested until recently. The relevant empirical questions are: 1) is it true that people always share the same intuitions concerning these cases and 2) is the principle of double effect the result

7 For more details see Mikhail, John, op. cit., n. 5, 2000. 
of operative or explicitly understood mental representations?

The answers to these questions, provided in a study by Marc Hauser et al., are surprising. ${ }^{8}$ Hauser et al. used trolley cases and asked subjects to determine if killing one individual would be morally permissible for the sake of saving five individuals. The 'side effect' condition describes a situation were an individual has to mechanically turn a train and, as a consequence, one person is killed. If the train is not turned, then five people die. In the 'necessary means' condition the person has to physically shove a person to the tracks, saving five people. If the person is not shoved to the tracks, then the five people perish.

With respect to question (1) they found that "patterns of moral judgments were consistent with the principle of double effect and showed little variation across differences in gender, age, educational level, ethnicity, religion or national affiliation". ${ }^{9}$ It is worth mentioning that this result is not only very robust, in the sense that little cross-cultural variation occurred, but also quite significant: $85 \%$ of the subjects judged as morally permissible the death of one individual as a foreseeable side effect, but only $12 \%$ judged as morally permissible the same outcome when it was described as a necessary means for saving five people.

With respect to question (2), Hauser et al. found that "a majority of subjects failed to provide justifications that could account for their judgments" and interpreted this result as evidence that the principle of double effect may be operative, rather than explicitly understood, and thus not open to introspection. These results are indeed compelling evidence of a strong bias towards certain moral evaluations that seems to be present across cultures. But should we jump to the conclusion that these results are also evidence

8 Hauser, M. et al., Mind and Language 22(1), 2007, 1-21. I will omit important details of this experiment for the sake of brevity. However, those details are not relevant to the main topic of this paper.

9 Hauser, M. et al., op. cit., n. 8, p. 1. 
of UMG, or a moral sense? Let us start by considering the type of moral scenario that trolley cases present.

One obvious objection to this study is that it did not test subjects in real social or cultural scenarios. The trolley cases are highly abstract and artificial scenarios and their use in an experiment on our moral competence must be explained and justified. Hauser, et al. offer very good reasons to use abstract cases, such as trolley cases, instead of real scenarios. They explain:

First, by using artificial cases we can guarantee that subjects will have no familiarity with or personal attachment to the particular details of the case. Second, each case can be modified in critical ways in order to isolate salient dimensions. Consequently, the use of artificial moral dilemmas to explore our moral psychology is like the use of theoretical or statistical models with different parameters. The use of artificial dilemmas also parallels the use of artificial utterances to explore the structure of our linguistic intuitions, or the use of black and white grating patterns and line orientations to explore the psychophysics of vision. Third, philosophers have derived fundamental descriptive and normative principles by considering their own personal intuitions in response to these cases. By using these moral dilemmas as psychological probes, it is possible to test whether the intuitions of professional philosophers align with those of a larger and more diverse group of people. ${ }^{10}$

These are satisfactory replies to the aforementioned objection. I would add that it is very advantageous to run experiments with abstract scenarios, such as trolley cases, because emotional or aesthetic considerations, which might play a role in real moral scenarios, can be excluded as well, revealing a truly general principle for moral competence -in this case the principle of double effect.

A more serious objection to the Hauser, et al. study concerns their interpretation of the data, which goes back to

10 Ibidem, p. 4. 
the question I raised before: should we conclude that these results say anything about UMG? Particularly, why should the principle of double effect reveal something about UMG and not, for instance, about mechanisms for judging scenarios that are not relevant to moral judgment? To know if the principle of double effect is relevant to UMG, we need to know more about what principles constitute UMG and then determine how the principle of double effect is relevant to the computation of these principles. In his review of Marc Hauser's recent book on UMG, Moral Minds, Michael Waldmann challenges that Hauser's interpretation of the data on the principle of double effect seems ad hoc because the alleged principles of UMG are poorly stated and thus, it is difficult to see the connection between the principle of double effect and UMG. Waldmann writes,

Hauser argues that we are endowed with an abstract universal moral grammar with parameters that encode cultural differences. The moral grammar along with a variety of cognitive competencies underlies our morality. Unfortunately, Hauser never explains what the rules and parameters of the moral grammar precisely look like. Findings that show that different cultures generate similar intuitions (as in the trolley problems) are viewed as evidence for universal rules, whereas other studies showing huge cultural differences are interpreted as evidence for the role of parameters. This flexibility of the theory makes it hard to envision what could constitute a strict empirical test of the theory. ${ }^{11}$

It is clear that studies demonstrating huge cultural variation in moral practices should not be assumed to be consistent with the UMG hypothesis. At least not without a clear elaboration of how the principles of UMG, or I-morality, are instantiated through parametric variations in very different E-moralities.

E-moralities and their official enforcement through legal systems must be structured by I-morality in a principled

11 Waldmann, M., “A Case for the Moral Organ?”, Science 314, 2006, p. 57. 
way. The linguistic analogy predicts that E-moralities and moral behaviors in general bear a structural relation to UMG. But while the differences in E-languages have been shown to be mostly superficial, thus revealing a truly universal grammar that frames all of them, studies on E-moralities, or concrete moral behaviors in different cultures, show differences that do not seem superficial. ${ }^{12}$ In order to draw the linguistic analogy in a plausible way, cultural differences need to be proven superficial, as was the case with UG. So far, there is no compelling reason to think that the cultural differences of E-moralities are superficial and that UMG structures all moral behavior. Furthermore, drawing the linguistic analogy will depend on a clear understanding of the principles underlying UMG and their alleged relation to particular E-moralities, which remains an unsolved problem.

Another problem with Hauser's interpretation of the data on the principle of double effect is that there are many mechanisms that are relevant to moral judgment, such as emotional and mind-reading mechanisms that could account for some of the trolley cases' results. However, it is far from clear that these mechanisms are exclusively devoted to moral cognition or that there is a unique mechanism for our moral sense, which is the thesis that Hauser defends in his book. The data presented by Hauser is compatible with the thesis that there is no unique mechanism responsible for our moral sense, but rather a collection of mechanisms that perform many morally relevant computations, none of which is exclusively devoted to morality. I will revisit this issue, which actually stems from Hauser's own work in collaboration with Chomsky, in section V.

However, in spite of these objections, Hauser's et al. experiment is quite important. It is the first experiment that provides significant support to the idea that we have a

12 See for example Henrich, J. et al., " Economic Man” in Cross-cultural Perspective: Behavioral Experiments in 15 Small-scale Societies”, Behavioral and Brain Sciences 28 (6), 2005, 795-855. 
moral sense or UMG, which could be considered the basis for Natural Law. For the sake of argument, I will assume that there is indeed a moral competence that biases us towards certain interpretations of moral stimuli. Should this cognitive capacity be relevant to moral and legal theory? Even if the Hauser et al. experiment proves that we have innate principles that ground moral intuitions without our being aware of them, should these moral intuitions be the basis of a theory of moral and legal obligations? This is the main question that I address in the following section.

\section{Second PROBlem: InTUitionism ANd UMG}

The use of intuitions in philosophy is a topic of much debate. I will focus on the use of intuitions in morality, which raises a new set of issues and objections to the idea that UMG is the basis of Natural Law and moral judgment. I first assess an objection by Peter Singer concerning intuitionism and skepticism about ethics and then offer a stronger objection, based on Peter Unger's argument against intuitionism in moral reasoning.

Peter Singer (2005) argues that although research on the cognitive basis of our moral intuitions is very important, for instance by showing how these intuitions are not theoretically or introspectively generated, the ethicist is still faced with a choice concerning the nature of moral judgment. And the choice is a difficult one, since it is to either accept a form of moral skepticism or to insist that moral judgments are necessarily rational and normative. He describes this choice as follows:

Kant thought that unless morality could be based on pure reason, it was a chimera. Perhaps he was right. In the light of the best scientific understanding of ethics, we face a choice. We can take the view that our moral intuitions and judgments are and always will be emotionally based intuitive responses, and reason can do no more than build the best possible case for a decision already made on nonrational 
grounds. That approach leads to a form of moral skepticism, although one still compatible with advocating our emotionally based moral values and encouraging clear thinking about them. Alternatively, we might attempt the ambitious task of separating those moral judgments that we owe to our evolutionary and cultural history, from those that have a rational basis. This is a large and difficult task. Even to specify in what sense a moral judgment can have a rational basis is not easy. Nevertheless, it seems to me worth attempting, for it is the only way to avoid moral skepticism. ${ }^{13}$

The contrast Singer is making is between Kantian and Humean approaches to morality and, thus, is orthogonal to any consideration about UMG. However, the studies on moral intuitions Singer is referring to were conducted mainly by Joshua Green and Jonathan Haidt, and are based on the same trolley scenarios used by Hauser, et al. Green and Haidt interpreted these results as evidence of emotionally based intuitions. As mentioned, it is not entirely clear that the data on trolley scenarios reveals rational principles. Rather, the fact that these principles are operative suggests the contrary: that they are a type of gut reaction or nonrational response to stimuli. And it is for this reason that Singer's objection holds against the UMG hypothesis too.

An advocate of UMG might reply that this objection is misplaced. The moral grammar, like UG, is neither rational nor emotional. It is simply an abstract structure through which we syntactically determine representations, and produce new chains of grammatical representations. However, if Singer is right, UMG would also lead to a type of moral skepticism, not because it appeals to our emotions, but because it makes our evolution and cognitively innate make up the basis of moral judgments. Our evolution and cognitive make up are contingent. Yet, morality is supposed to be not contingent upon our cognitive evolution. This is why

13 Singer, Peter, "Ethics and Intuitions", The Journal of Ethics 9, 2005, 331-352, p. 351. 
Kant is relevant here, because if morality is not based on reason, then it is a chimera. Why? Because how we ought to act cannot be reduced to how we evolved or how our brain is wired. Intuitions might be indispensable for moral judgment, but only if they are framed normatively and rationally. And this is crucial to answer the question "what constitutes I-morality?", which is problem 1 of the linguistic analogy.

Nevertheless, the UMG advocate would insist, how we ought to act depends upon mental representations concerning agents, goals and moral permissibility. And UMG is crucial to understand how we construct these mental representations. You can call these representations 'intuitions' or 'gut reactions'. What matters is that they are representations that seem to be universal and directly related to moral permissibility. If one grants that UMG is the cognitive basis of moral permissibility, skepticism aside, is there another problem concerning UMG and its relation to moral judgment?

Another important objection to the use of intuitions in ethics is that they actually mislead us into thinking that some acts are morally neutral or permissible when they are indeed morally reprehensible. Peter Unger's (1996) 'liberationist' approach to ethics is based on this idea. ${ }^{14}$ Unger argues that it is immoral not to lessen the serious suffering of people that are distant, geographically or socially. Through a series of imaginative thought experiments, he shows how our intuitions mislead us into thinking that not making small pecuniary sacrifices to significantly lessen the serious suffering of the distant needy is not immoral. Unger disagrees, and argues that such behavior is morally reprehensible. In order for us to act morally we need to liberate ourselves from these intuitions and realize that not lessening the serious suffering of the distant needy is highly reprehensible. Without entering into the details of Unger's pro-

14 Unger, Peter, Living High and Letting Die-Our Illusion of Innocence, New York, NY. Oxford University Press, 1996. 
posal, I will focus on the most important aspects of his liberationist approach, and then explain how they relate to UMG.

A key proposal presented by Unger is that the salience or conspicuousness of those in need plays a very significant cognitive role in our decision-making. Letting someone die who is close to you, physically or socially, is intuitively wrong, whereas letting someone die because of famine in a situation where the person in need is not salient to you (because of physical and social distance) is not intuitively wrong. It might not be intuited as right either, but at least it is still considered permissible behavior. Thus, our intuitions lead us to behave immorally, allowing the death of hundreds of innocent people. However, we think that our behavior is morally permissible. This is the reason why we need to resist, or liberate ourselves from, our intuitions or immediate reactions to moral scenarios and think through the consequences of our acts.

The way in which Unger's liberationist proposal could be used against UMG is that these intuitions that mislead us into acting badly seem to be based on operative principles. No experiment, as far as I know, has tested Unger's scenarios. However, if people generally intuit that it is permissible to let die the distant needy based on operative principles, then UMG, which is the set of these principles, would lead us to act immorally. And this would be terrible because UMG would be an obstacle to clear thinking and reasoning concerning how we ought to act.

This way of criticizing the UMG hypothesis highlights a problem that I think is also present in Singer's objection, namely, that moral judgment and moral behavior cannot be based on sub-personal or operative principles that are not accessible to introspection. It seems that introspection is really crucial to morality. Introspection and the notion of reflective equilibrium are actually at the core of Rawls' theory of justice, particularly when he describes the original position. Why should we call 'moral' operative principles 
that are not available through introspection? The relation between operative and express principles is thus problematic, particularly concerning moral content. However, one way in which the UMG theorist can get out of this line of objection is as follows.

There is evidence that confirms robust discrepancies in our evaluations of moral scenarios. The best explanation of these data is that there is an innate set of principles (UMG) concerning moral judgment. Exactly how these principles relate to moral behavior and introspection is a topic that needs more theorizing. But at the moment, stating that UMG is the basis of our moral competence is the best explanation we have of the data available.

I will assume that this is a fair enough reply to the previous objections. What makes it particularly appealing is the evidence collected from the experiments plus the fact that it is indeed difficult to define what should count as 'moral'. It is worth mentioning that Singer and Unger think that our moral judgments should include moral agents that are generally excluded. Unger focuses on the needy and Singer goes even further, stating that we are morally obliged to lessen the unnecessary suffering of animals. It is important to stress how difficult it is to test intuitions concerning these very relevant moral obligations with the methodology of trolley cases. Unger explicitly criticizes the methodology of trolley scenarios, which are two-option cases, by saying that they provide very limited insight into our moral competence. ${ }^{15}$ This is of relevance to researchers working on moral psychology, who could benefit from adopting more complex moral scenarios.

Since the empirical evidence is what makes UMG appealing, in the next section I present and examine other experiments testing our moral competence and social behavior, its relation to our biological makeup and our evolution. I then explain how UMG relates to this research and conclude that the problems that arise from biological and evo-

15 Ibidem, 88. 
lutionary considerations for the UMG hypothesis constitute the most significant challenge concerning its plausibility.

\section{Third Problem: Evolution, Behavior and UMG}

Our behavior is the product of very complex biochemical processes. We are just beginning to understand the tremendous effect that slight variations in our biochemistry have on our behavior. The most dramatic illustrations of these effects are provided by behaviors that subjects cannot rationalize, explain, but most importantly, control even if they consciously try to, as in the case of Lesch-Nyhan syndrome. There are many behaviors that we cannot control, like the sleep-wake cycles governed by the circadian clock. What makes certain behaviors, such as those produced by the Lesch-Nyhan syndrome, so unique is that they involve what appears to be voluntary acts of the subject and yet, subjects report that their behavior is beyond their reach. The National Institute of Neurological Disorders and Stroke defines Lesch-Nyhan syndrome as follows:

Lesch-Nyhan syndrome (LNS) is a rare, inherited disorder caused by a deficiency of the enzyme hypoxanthine-guanine phosphoribosyltransferase (HPRT). LNS is an X-linked recessive disease- the gene is carried by the mother and passed on to her son. LNS is present at birth in baby boys. The lack of HPRT causes a build-up of uric acid in all body fluids, and leads to symptoms such as severe gout, poor muscle control, and moderate retardation, which appear in the first year of life. A striking feature of LNS is self-mutilating behaviors characterized by lip and finger biting - that begin in the second year of life. Death is usually due to renal failure in the first or second decade of life. 16

Subjects with LNS bite their lips and fingers to the point that they sever them. Many patients have to be restrained

16 http://www.ninds.nih.gov/disorders/lesch_nyhan/lesch_nyhan.htm. 
in order for them not to seriously hurt themselves. Some subjects report that their hand "moves" toward their mouth and they feel an overwhelming fear that makes them bite their fingers. One could think that these patients are suicidal or mentally ill. They clearly have representations of what is happening and know that self-mutilation is a socially shocking behavior. But they cannot control themselves and science has revealed that the explanation is in the genes of these patients.

Clearly, our moral behavior cannot be the mere result of biochemical processes and UMG actually explains why, namely, because there must be abstract computational principles that involve representations for moral behavior to exist. Granted, these computational principles are instantiated in our biochemistry, but they cannot be reduced to such biochemistry. So, the purpose of mentioning LNS is to exemplify just how significant is the impact of our biological make up on our behavior, not to deny that there are computational principles involved in social behavior.

Because of the importance of biological processes, many biologists and cognitive scientists, including Marc Hauser, have been intrigued by the evolution of our social behavior and its possible biological basis. One line of research, which focuses on computational structures such as UMG, investigates the innate basis of abstract moral judgments, its evolution and probable neurological instantiation. Another line of research focuses on concrete behaviors and social settings, trying to predict the behavior of social agents in order to confirm theoretical hypotheses.

It would be ideal if the studies on real behavior supported the studies on abstract moral judgments, because that would be strong evidence in favor of the linguistic analogy. Languages that on the surface seem quite different have been, after examination, confirmed to have a general common structure, as UG predicts. If the linguistic analogy is true, we should find that drastically different social settings reveal an underlying abstract structure, as UMG predicts. 
However, the evidence on how humans and primates behave in real social settings is distressing, to say the least, and seems to challenge the hypothesis that abstract moral principles play a significant role in determining social behavior. What can be called "universal" about these real-scenario studies is that in all of them violence and cruelty play a disturbingly significant role.

I will start with a set of observations made by biologist Michael P. Ghiglieri, who worked with Jane Goodall observing chimps in the Kibale rain forest. ${ }^{17}$ Ghiglieri was expecting chimps to be cooperative and peaceful. He found out that chimpanzee males routinely kill other chimpanzees and primates. This is common behavior among other species. However, what was shocking was the level of violence and cruelty used in territorial supervision routines. Other males and baby chimps were killed to get the females ready for reproduction. Invaders of a chimp community's territory are brutally killed by male members. These observations are important because chimps and primates are our closest evolutionary relatives. Studying them in labs reveal precious information about the evolution of our cognitive capacities, but studying them in real scenarios brings to light something we share with them too, violence and cruelty, which is difficult to study under the controlled conditions of a laboratory.

In another book, Ghiglieri focuses on violence in humans, and offers evidence showing that male violence is largely innate and the product evolution. ${ }^{18}$ His book has very disturbing recommendations for legislation that I deeply disagree with, but the evidence he offers is what matters. He touches on genocide, rape, war, gang violence and murder and suggests that these cruel and incomprehensibly violent behaviors are firmly rooted in our evolution. Males are

17 Ghiglieri, Michael, East of the Mountains of the moon: Chimpanzee Society in the African Rain Forest, New York, NY: The Free Press, 1988.

18 Ghiglieri, Michael P., The Dark Side of Man: Tracing the Origins of Violence New York, NY. Perseus Publishing, 1999. 
more violent than females because we lived in groups in which raping and murdering were advantageous reproductive strategies. Similar reasons are offered for gang violence and war.

Although disturbing, the evolution of violence and its genetic basis could still be compatible with UMG. Maybe we act violently because of our evolution, but we might also have an innate moral sense, which could be the basis of legislation and moral behavior. However, it is important to emphasize that there is a gigantic gap between the imagined worlds of two-option trolley scenarios and the real social settings in which rape and murder occurs. How exactly does UMG relate to the cognitive mechanisms responsible for violence? Is violence a parameter of UMG? There are no clear answers to these questions so far.

There are two controversial studies that support the thesis that behavior needs to be studied in realistic social settings because of the tremendous influence that these settings have on our decision-making. Even if we ignore the violence produced by rage or reproductive drive, there is a disturbing trend of disregard for human pain that shocked the researchers involved in these studies. The first of them was conducted by Stanley Milgram in 1963.19 The social setting was an asymmetric and anonymous one: the subject is a "teacher" who is instructed by the experimenter to give electric shocks to "learners", who are actors that provide answers remotely, from another room. The voltage of the electric shock was increased with each wrong answer and the subjects believed that the shocks were real. There are many interesting aspects and versions of this experiment, but the most relevant result is that, against Milgram's expectation that only a few sadistic individuals (1.2\%) would inflict a fatal voltage, actually $61 \%$ of the subjects decided to inflict the fatal voltage.

19 The most relevant aspects of this experiment are described in Milgram, Stanley, Obedience to Authority: An Experimental View, New York, NY. HarperCollins, 1974. 
Philip Zimbardo conducted another study in a realistic setting, this time a "prison" where some students were the guards and other students the prisoners. His results are equally shocking. ${ }^{20}$ Conducted in 1971 at Stanford University, the "prison experiment", which was planned for two weeks, had to be abruptly ended because guards became sadistic in just a few days. Guards humiliated prisoners, even though they knew they were students, just like them. Beliefs about their being students were simply suspended or ignored, both by guards and prisoners. Prisoners felt depressed and stressed, and some had to be reminded that it was only an experiment that could be ended at any point.

The Zimbardo and Milgram experiments reveal troubling aspects of our social behavior. These experiments suggest the use of operative principles by their participants, principles that are not only difficult to articulate, but beyond justification upon introspection. ${ }^{21}$ Why is it that sadistic behavior 'kicks in' when we are put in an asymmetric social setting? This is a very important question concerning how UMG or any social representation concerning morality is put to use (problem 3 of the linguistic analogy). But it is also very relevant to the problem of how our moral sense was developed or acquired during our evolution (problem 2 of the linguistic analogy), because it seems that power relations and social asymmetry are very important when it comes to actual behavior.

Another important point that deserves attention is that in order to put to use UMG, we need subjects to experience a social context, which cannot be achieved by verbally telling

20 See Haney, C. et al., "Interpersonal dynamics in a simulated prison", International Journal of Criminology and Penology, 1, 69-97, 1973; Haney, C., Banks, W. C., and Zimbardo, P. G., "Study of prisoners and guards in a simulated prison", Naval Research Reviews, Washington, D. C., 9 (1-17), 1973; and Zimbardo, P.G., The Lucifer effect: Understanding How Good People Turn Evil, New York, NY, Random House, 2007. The website for the prison experiment is http://www.prisonexp.org/ slide-6.htm.

21 Maybe it is incorrect to call "operative" any principle that cannot be rationally justified. But since this is the standard used by Hauser et al., that is the standard I will employ here. 
them a story about a trolley that could kill 1 or 5 people. Again, there seems to be a gigantic gap between abstract moral reasoning and real social settings, just as there is a gigantic gap between theoretical ethics and the Holocaust. If sadistic behavior is the result of gut reactions to moral settings, or of operative principles that cannot be justified upon introspection, it needs to be clarified how they interact with the abstract computational principles that allegedly constitute UMG.

Notice that I am not objecting to the use of abstract scenarios to identify UMG-I actually defended their use in section III. The problem I am raising here concerns problems 2 and 3, which need to be answered from the E-morality point of view, and its evolution. It seems to me that any E-morality has built-in asymmetries, or relations of power that need to be accounted for. This is the relevance of the Milgram and Zimbardo studies.

Finally, with respect to evolution, UMG has unclear implications as to the status of moral agents. According to Fitch, Hauser and Chomsky's account of the faculty of language, it is possible that there is no uniquely human cognitive mechanism devoted to language. ${ }^{22}$ With respect to moral competence, if moral competence is the accidental outcome on not uniquely human cognitive mechanisms, then what happens to Rawls' original position and to the symmetry between moral agents required by moral principles? Should moral standing be based on a completely accidental jumble of mechanisms that are not uniquely human? If an animal has an almost identical moral competence to UMG, should it have moral standing?

Legal systems must rely on the notion of symmetry (equal rights for individuals) and exceptions to formal symmetry can only be justified by materially asymmetric conditions. But the reality of legal systems (instantiated in jails, courts, etcetera) requires also that we account for asymmetries, not

22 Fitch, W. et al., "The evolution of the language faculty: Clarifications and implications", Cognition 97, 2005, 179-210. 
only material (such as poverty) but also bureaucratic and structural, like those explored in the Milgram and Zimbardo studies. In future research, finding the relation between the symmetric principles that underlie abstract moral reasoning and provide equal moral standing, and the asymmetric power structures in which humans live will be fundamental to answer questions 2 and 3 of the linguistic analogy. The problem of moral standing is a very controversial issue. Should it include animals, other morally competent agents, embryos, etc? I do not expect the theorists defending UMG to provide answers to all these questions. However, moral standing and moral competence go hand in hand and it would be useful to postulate some tentative theses as to how UMG should be interpreted with respect to moral standing.

\section{CONCLUSION: LAW AND UMG}

Research on UMG and moral innatism in general provides a unique and fresh approach to traditional problems concerning the foundations of morality and normativity. For the first time, cognitive science is allowing psychologist to probe empirically the border between nature and nurture. UMG is an ambitious and suggestive hypothesis that, without a doubt, will generate interesting and controversial research in the future. In this article, I offered three different types of problems that UMG theorist must face. For legal theorists, the most important conclusions to bear in mind concerning the current debate on UMG are the following.

First, psychological evidence will be very relevant to assess the plausibility of traditional legal theories. UMG is already giving significant support to the view, endorsed by Natural Law theories, that we share a universal moral sense that grounds morality and legislation. However, even if UMG is verified by more experiments, there are very important issues to address, some of which I described in this paper. It is possible that our complex social behavior re- 
quires insights from both Natural Law theories and positivism. The Milgram and Zimbardo experiments show that social settings have a tremendous impact on our social behavior. Rousseau's noble savage and Hobbes' naturally evil human might turn out to be both right, melted into our social representation of the world. The fact that power is such an important ingredient in moral decision-making vindicates the positivistic view that legal systems have their justification in the monopoly of power.

Second, the borderline between nature and nurture can be explored with scientific evidence and legal theorists should not take a totalitarian and aprioristic approach to these issues. In this article I tried to highlight problems with an innatist approach to morality and social normativity. However, this does not mean that such an approach is wrong or that it will not provide insightful lessons for lawyers. It is already provoking lively debate and it is likely to continue doing so.

Third, cognitive science has and will have a fundamental role in legal theory and practice. Neuroscience has already transformed the way in which juries and judges consider evidence. Brain tumors have been identified as sources of criminal behavior and the fact that their removal stops such behavior has turned the research of neuroscientist into evidence for exculpation. As mentioned, hypotheses like UMG will have an impact on the plausibility of legal theories, such as Natural Law doctrines. These are exciting times for lawyers and legal researchers, but at the same time, the challenge of keeping up with cognitive scientific findings is demanding. Lawyers and legal theorist have now the responsibility to look beyond their field, and start taking a more proactive role in the interdisciplinary study of social behavior. 